\title{
Functional decline in the elderly with MCl: Cultural adaptation of the ADCS-ADL scale
}

\author{
Fabiana Carla Matos da Cunha Cintra ${ }^{1 *}$, Marco Túlio Gualberto Cintra² ${ }^{2}$ Rodrigo Nicolato ${ }^{3}$, Laiss Bertola ${ }^{4}$, \\ Rafaela Teixeira Ávila ${ }^{4}$, Leandro Fernandes Malloy-Diniz ${ }^{5}$, Edgar Nunes Moraes ${ }^{6}$, Maria Aparecida Camargos Bicalmo \\ ${ }^{1}$ Occupational Therapist and MSc in Neuroscience from Universidade Federal de Minas Gerais (UFMG), Belo Horizonte, MG, Brazil \\ ${ }^{2} \mathrm{PhD}, \mathrm{MD}$, Geriatrician at Instituto Jenny de Andrade Faria de Atenção à Saúde do Idoso, Hospital das Clínicas (HC) da UFMG, and MSc in Sciences applied to Adult Health from UFMG, Belo Horizonte, MG, Brazil \\ ${ }^{3}$ Adjunct Professor, Department of Mental Health, Faculdade de Medicina da UFMG. Member of the Instituto Nacional de Ciência e Tecnologia de Medicina Molecular (INCT-MM), Belo Horizonte, MG, Brazil \\ ${ }^{4}$ Neuropsychologist at Instituto Jenny de Andrade Faria de Atenção à Saúde do Idoso, HC-UFMG, and MSc in Molecular Medicine from UFMG, Belo Horizonte, MG, Brazil \\ ${ }^{5}$ Adjunct Professor, Department of Mental Health, UFMG, and Coordinator of the Neuropsychology Service at Instituto Jenny de Andrade Faria de Atenção à Saúde do Idoso, HC-UFMG. Member of the INCT-MM, \\ Belo Horizonte, MG, Brazil \\ ${ }^{6}$ Associate Professor, Department of Internal Medicine, UFMG, and Coordinator of the Geriatric Outpatient Clinic at Instituto Jenny de Andrade Faria de Atenção à Saúde do Idoso, HC-UFMG, Belo Horizonte, MG, Brazil \\ ${ }^{7}$ Adjunct Professor, Department of Internal Medicine, UFMG, and Subcoordinator of the Geriatric Outpatient Clinic at Instituto Jenny de Andrade Faria de Atenção à Saúde do Idoso, HC-UFMG. Member of the INCT-MM, \\ Belo Horizonte, MG, Brazil
}

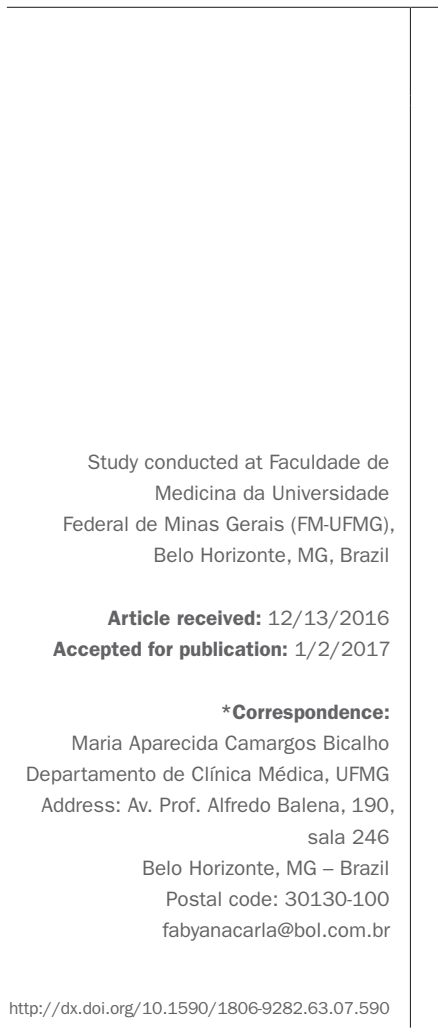

\section{SUMmARY}

Objective: Translate, transcultural adaptation and application to Brazilian Portuguese of the Alzheimer's Disease Cooperative Study - Activities of Daily Living (ADCS-ADL) scale as a cognitive screening instrument.

Method: We applied the back translation added with pretest and bilingual methods. The sample was composed by 95 elderly individuals and their caregivers. Thirty-two (32) participants were diagnosed as mild cognitive impairment (MCI) patients, 33 as Alzheimer's disease (AD) patients and 30 were considered as cognitively normal individuals.

Results: There were only little changes on the scale. The Cronbach alpha coefficient was 0.89 . The scores were 72.9 for control group, followed by MCI (65.1) and by AD (55.9), with a p-value < 0.001 . The ROC curve value was 0.89 . We considered a cut point of 72 and we observed a sensibility of $86.2 \%$, specificity of $70 \%$, positive predictive value of $86.2 \%$, negative predictive value of $70 \%$, positive likelihood ratio of 2.9 and negative likelihood ratio of 0.2 .

Conclusion: ADCS-ADL scale presents satisfactory psychometric properties to discriminate between $\mathrm{MCI}, \mathrm{AD}$ and normal cognition.

Keywords: mild cognitive impairment, Alzheimer's disease, activities of daily living.

\section{INTRODUCTION}

An accelerated aging process in the population can be observed in both developed and developing countries. In Brazil, from 1940 onwards, the aging process has increased morbidity and mortality due to external causes and chronic-degenerative diseases, such as dementia. ${ }^{1}$ The evolution of these diseases is often marked by the progressive decline in functional capacity, with consequent impairment of quality of life. ${ }^{1-3}$

According to the World Alzheimer Report (2011), more than 65 million people worldwide have dementia,
$58 \%$ of which live in underdeveloped countries. This research also reveals that studies conducted over the last 10 years have shown that only one fifth of dementia cases are routinely recognized and documented in developed countries. In underdeveloped countries, such as Brazil, the situation is even more serious, as up to $90 \%$ of the relatives of patients with this clinical condition had not even received guidelines regarding the disease and available treatments. ${ }^{2,4}$

In recent years, mild cognitive impairment $(\mathrm{MCI})$ has been recognized as an intermediate stage between normal 
cognition and dementia. ${ }^{5} \mathrm{MCI}$ indicates that the affected individual presents greater chances of conversion to dementia caused by Alzheimer's disease (AD) and other degenerative processes than individuals with normal cognition for their educational level. ${ }^{5}$

MCI usually affects one or more domains of cognition, and is classified into the amnestic and non-amnestic subtypes, according to the presence or absence of memory impairment. The amnestic type is mainly characterized by memory complaints and may reflect $\mathrm{AD}$ in the pre-dementia symptomatic phase. The non-amnestic type is characterized by deficits in any other domain of cognition, for example, executive function, reasoning, attention, and more. ${ }^{5}$ The latter, most often progresses to other forms of dementia (not $\mathrm{AD})$. $^{6-8}$

According to Bagen et al., elderly people with MCI present difficulties in the performance of activities of daily living (ADL). ${ }^{9}$ However, there are problems related to the identification and classification of the activities involved. Subtle deficits were identified in advanced and instrumental ADL, which would generally go unnoticed, compromising quality of life and determining the risk of conversion to $\mathrm{AD}$.

Functionality may represent an important marker in the differential diagnosis between individuals with normal cognition and amnestic MCI. However, the existing instruments for functional assessment are heterogeneous, making comparisons difficult. Most tests used are not validated and culturally adapted for use in the Brazilian population with MCI. In addition, doubts remain as to which ADL are compromised and how best to assess them. ${ }^{9-13}$

In this context, the purpose of this article is to report the results of the process of translation, cross-cultural adaptation and application of the Alzheimer's Disease Cooperative Study - Activities of Daily Living (ADCS-ADL) scale as an instrument for evaluating the functionality of the Brazilian population for the diagnosis of dementia and its non-dementia clinical phase, also known as MCI.

\section{Method}

This is a cross-sectional study in which individuals were recruited from June 2012 to May 2013 by convenience sampling obtained at the Mild Cognitive Impairment outpatient clinic of the Jenny de Andrade Faria Institute for Elderly Care at the Federal University of Minas Gerais (UFMG) Clinics Hospital. All of the participants and/or their companions/caregivers signed the informed consent form (ICF). This study was approved by the UFMG Research Ethics Committee under no. 0318.0.203.000-11.
The ADCS-ADL scale was created in 1997 by Galasko et al. ${ }^{14}$ It is a questionnaire with 23 Likert-type questions for functional assessment, in which the subject must express their degree of agreement or disagreement with the questions in the questionnaire (independent, partially independent and totally dependent). It is adapted for elderly people with MCI and it is completed based on the data provided by an informant. The questionnaire describes the performance of patients in the prior month in various activities: Basic (BADL), instrumental (IADL) and advanced (AADL) ADL. ${ }^{15,16}$

The procedure for translation and cultural adaptation followed an internationally accepted protocol proposed by Beaton et al. ${ }^{17}$ The technique used was back-translation associated with the bilingual method, following five stages, namely, two independent translations, synthesis of the Portuguese translations, back translation of the scale into English, and analysis of the questionnaire by a panel of expert judges. The pre-final version was then submitted to pre-testing.

For pre-testing, a sample consisting of 90 Brazilian elderly people living in the community and their respective caregivers or informants was divided into three groups containing 30 individuals each: cognitively normal controls, amnestic MCI patients, and patients with probable early stage $\mathrm{AD}$. The application of the questionnaire was timed.

We included 95 individuals aged 60 years or older with normal cognition, MCI or AD. The diagnosis of probable sporadic $\mathrm{AD}$ followed the criteria of Mckhann et al., classified as mild, stage 1 by the Clinical Dementia Rating (CDR). ${ }^{18,19}$ For MCI, the criteria defined by Albert et al. and Petersen et al. were used. ${ }^{5,20}$ This group only included patients with the amnestic form. The control group consisted of individuals with normal cognition considering the specific cut-off points according to educational level.

Individuals with non-Alzheimer's dementia, moderate or advanced AD, psychiatric illness, Parkinson's disease, delirium and MCI secondary to other causes (psychiatric disorders, endocrine-metabolic diseases, autoimmune diseases, traumatic brain injury, drugs, alcohol and drugs) were excluded. We also excluded subjects with impaired mobility, vision or hearing deficits, and those who did not complete all of the assessments. We did not include individuals whose companion and/or caregiver were not present at the assessment interview.

For an adequate assessment of cognition and allocation of individuals to the groups described, all patients underwent evaluation by geriatricians and neuropsychologists trained in cognitive assessment of the elderly. 
All subjects were submitted to the same study protocol. In order to rule out other causes of cognitive decline and to diagnose concomitant diseases, laboratory and structural and functional neuroimaging examinations (nuclear magnetic resonance or computed tomography of the brain and/or positron emission tomography - PET-CT of the brain) were performed. In all cases, the clinical and neuropsychological diagnoses were concordant.

The following tests were used to assess cognition, mood, functionality and caregiver overload: Mini-Mental State Examination $^{21}$ (MMSE), verbal fluency test - fruit and animal category, ${ }^{22}$ Geriatric Depression Scale - 15 -item version, ${ }^{23}$ the clock test ${ }^{24}$ word list from the Consortium to Establish a Registry for Alzheimer's Disease (CERAD) ${ }^{25}$ Behavioral Pathology in Alzheimer's Disease Scale - BEHAVE-AD, ${ }^{26}$ the Pfeffer Instrumental Activities Questionnaire, ${ }^{27}$ the List of Figures, ${ }^{28}$ Clinical Dementia Rating (CDR), ${ }^{19}$ the apathy scale, ${ }^{29,30}$ functional stating using the Functional Assessment Staging (FAST), ${ }^{31}$ the Neuropsychiatric Inventory (NPI), ${ }^{32}$ and the DSM-IV Criteria for Depressive Disorder. ${ }^{33}$

Regarding the neuropsychological assessment, cognitive tests were applied considering the low educational level of the study population, based on the service's protocol, as described below: The Mattis Dementia Rating Scale, ${ }^{34,35}$ the Digit Span test, ${ }^{36}$ the Corsi Cubes, ${ }^{37,38}$ Token Test, ${ }^{39,40}$ and Rey's Auditory-Verbal Learning Test - RAVLT. ${ }^{41-44}$

The Shapiro-Wilk test was used for normality analysis. The distribution of the sample was considered normal only for the age of the informant variable. Chi-square, Anova and Kruskal-Wallis tests were used as non-parametric tests. To verify correlations between continuous variables, we used Spearman correlation test.

Descriptive and analytical statistics; quality of clinical trials: sensitivity (Se), specificity (Sp), negative (NPV) and positive (PPV) predictive value, positive (PLR) and negative (NLR) accuracy and likelihood ratio; ROC curve (to establish the cut-off point) and Cronbach's alpha (internal consistency) were performed in order to determine reliability. The data obtained was analyzed using the SPSS statistical software version $19.0, \mathrm{IBM}^{\circledR}$.

\section{Results}

Translation and cultural adaptation of the ADCS-ADL Questionnaire

The process of translation and adaptation of the questionnaire showed satisfactory results, indicating semantic equivalence between the two translations and absence of translation difficulties, verified by the small number of modifications carried out by the expert committee. The changes involved: formatting of the questions (47\%), cul- tural expressions (29\%) and vocabulary (17\%). Other changes totaled $7 \%$. These items were modified or had their format changed in order to facilitate cultural understanding and appropriateness. These changes did not result in significant change to the scale. One subitem to a question (question 24) was added and the score changed from 78 to 79 points.

During the pre-testing application, a statistical difference was observed between the control and AD groups in the subdomain BADL, composed of self-care and feeding activities. This relation was not expected since the decline in BADL only occurs in the more advanced stages of AD. Analyzing the items in this subdomain, we observed that "select/choose clothes" and "eat using forks and knives" were responsible for this difference, since they obtained lower scores when compared to the other items of the BADL subdomain, probably due to the influence of gender in these tasks.

To minimize this bias, we modified the item "eating using forks and knives" to "eating independently" and removed the item "select/choose clothes," given that even among men in the control group, this activity was performed by a third party, usually the wife or daughter. We observed that for many elderly people the activity of selecting clothes is delegated to the spouse, constituting a pattern of dependence cultivated by personal habits. These modifications to correct the influence of gender did not cause a change in the final score of the questionnaire.

Considering the expert opinions and pre-testing, we constructed the Brazilian version of the ADCS-ADL.

\section{General characteristics of the sample selected for pre-testing}

The 95 participants selected were allocated into three groups: 30 controls, $32 \mathrm{MCI}$ and $33 \mathrm{AD}$. Regarding the MCI group, all of the patients presented the amnestic subtype, with $73 \%$ involving multiple domains and $27 \%$ a single domain. The sociodemographic data and the comorbidities of the participants are listed in Table 1.

Regarding the characterization of the control, MCI and $\mathrm{AD}$ groups, we noted a level of statistical significance and difference among groups in the age $(\mathrm{p}=0.020)$ and educational level $(\mathrm{p}=0.037)$ variables. The $\mathrm{AD}$ group, compared to others, was older (78.6 \pm 6.6$)$ and presented lower educational level (3.6 \pm 3.2$)$. As for comorbidities, $79.3 \%$ of the total sample had high blood pressure (HBP), 38.7\% dyslipidemia, 21.5\% type 2 diabetes mellitus (T2DM) and $20.4 \%$ had major depressive disorder. The depression variable showed a statistical difference among groups $(\mathrm{p}=0.028)$. Regarding caregiver characterization, the groups were similar in all of the evaluated variables, except age $(\mathrm{p}=0.015)$. 


\begin{tabular}{|c|c|c|c|c|c|}
\hline Variables & $\begin{array}{l}\text { Control group } \\
n=30\end{array}$ & $\begin{array}{l}\text { Group } \mathrm{MCl} \\
\mathrm{n}=32\end{array}$ & $\begin{array}{l}\text { Group AD } \\
n=33\end{array}$ & $\begin{array}{l}\text { Total } \\
\mathrm{n}=95\end{array}$ & p-value \\
\hline \multicolumn{6}{|l|}{ Sample data } \\
\hline \multicolumn{6}{|l|}{ Sex } \\
\hline Female (\%) & $63.3 \%$ & $65.6 \%$ & $51.5 \%$ & $60.0 \%$ & 0.461 \\
\hline Male (\%) & $36.7 \%$ & $34.4 \%$ & $48.5 \%$ & $40.0 \%$ & \\
\hline \multicolumn{6}{|l|}{ Education } \\
\hline (Mean $\pm S D$ in years) & $5.7 \pm 4.4$ & $5.2 \pm 3.9$ & $3.6 \pm 3.3$ & $4.8 \pm 3.9$ & $0.037^{*}$ \\
\hline \multicolumn{6}{|l|}{ Age } \\
\hline (Mean $\pm S D$ in years) & $73.4 \pm 7.9$ & $75.3 \pm 7.6$ & $78.6 \pm 6.6$ & $75.9 \pm 7.6$ & $0.020^{*}$ \\
\hline $\operatorname{HBP}(\%)$ & $79.3 \%$ & $65.6 \%$ & $84.4 \%$ & $76.3 \%$ & 0.190 \\
\hline T2DM (\%) & $20.7 \%$ & $18.8 \%$ & $25 \%$ & $21.5 \%$ & 0.824 \\
\hline Dyslipidemia (\%) & $41.4 \%$ & $43.8 \%$ & $31.3 \%$ & $38.7 \%$ & 0.554 \\
\hline Depression (\%) & $6.9 \%$ & $18.8 \%$ & $34.4 \%$ & $20.4 \%$ & $0.028^{*}$ \\
\hline \multicolumn{6}{|l|}{ Caregivers' data } \\
\hline \multicolumn{6}{|l|}{ Sex } \\
\hline Female (\%) & $74.3 \%$ & $75.0 \%$ & $90.0 \%$ & $80.0 \%$ & 0.147 \\
\hline Male (\%) & $25.7 \%$ & $25.0 \%$ & $10.0 \%$ & $20.0 \%$ & \\
\hline \multicolumn{6}{|l|}{ Education } \\
\hline (Mean $\pm S D$ in years) & $9.9 \pm 3.8$ & $8.7 \pm 3.1$ & $9.2 \pm 4.1$ & $9.2 \pm 2.6$ & 0.276 \\
\hline \multicolumn{6}{|l|}{ Age } \\
\hline (Mean $\pm S D$ in years) & $52.2 \pm 17.1$ & $55.0 \pm 13.0$ & $52.1 \pm 14.9$ & $53.1 \pm 14.9$ & $0.015^{*}$ \\
\hline \multicolumn{6}{|c|}{ Degree of family relations } \\
\hline Close relatives $(\%)^{* *}$ & $85.7 \%$ & $75.0 \%$ & $87.5 \%$ & $82.6 \%$ & 0.285 \\
\hline Other & $14.3 \%$ & $25.0 \%$ & $12.5 \%$ & $17.4 \%$ & \\
\hline
\end{tabular}

MCI: mild cognitive impairment; AD: Alzheimer's disease; SD: standard deviation; HBP: high blood pressure; T2DM: type 2 diabetes mellitus. significant difference.

"Close relatives: wife, husband, children or siblings.

The control group achieved higher mean scores in the MMSE tests (control: 26.5; MCI: 24.2 and AD: 19.3) and on the Mattis scale (control: 132.5; MCI: 119.1 and $\mathrm{AD}$ : 102.6). In relation to the MMSE variable, there was a significant difference only between the AD-MCI and AD-control groups ( $\mathrm{p}=0.001$ ). As for the Mattis scale, there was a significant difference in all groups $(\mathrm{p}<0.001)$.

Functionality, assessed by the Pfeffer and ADCS-ADL scales, presented a similar pattern of results to cognitive ability. Regarding the Pfeffer test, we observed greater independence in the control group $(0.4 \pm 0.7)$, greater dependence in the $\mathrm{AD}$ group $(10.6 \pm 7.2)$ and intermediate result in the MCI group (4.3 \pm 4.9$)$, with a statistical difference only detected between $\mathrm{AD}$ and $\mathrm{MCI}(\mathrm{p}=0.004)$.

The mean application time of the ADCS-ADL scale was 12 minutes. The control group showed a better score on the scale (72.9), followed by the MCI group, with intermediate performance (65.1). The $\mathrm{AD}$ group had the worst performance (55.9) ( $\mathrm{p}<0.001)$. As for the subitems in the ADCS-ADL scale, AADL and IADL presented a $p$-value $<0.001$, while BADL resulted in $p=0.004$. This difference is shown in Figure 1, which enables the detection of different functional profiles among the control, $\mathrm{MCI}$ and $\mathrm{AD}$ groups, showing mainly functional decline from the AD group to the MCI group, and from this group to the control group, especially regarding the IADL and AADL subitems.

As for the BADL subitem, despite the statistical difference observed, this was not clinically important due to very close values among the groups, especially considering the standard deviation. The AD group's result was $19.9 \pm 2.3$, MCI's $20.8 \pm 1.5$ and the control group's was $21.5 \pm 0.7$.

\section{Reliability}

The reliability of the Brazilian ADCS-ADL scale was obtained by analyzing the internal consistency coefficient of its 23 questions distributed in three subdomains: 


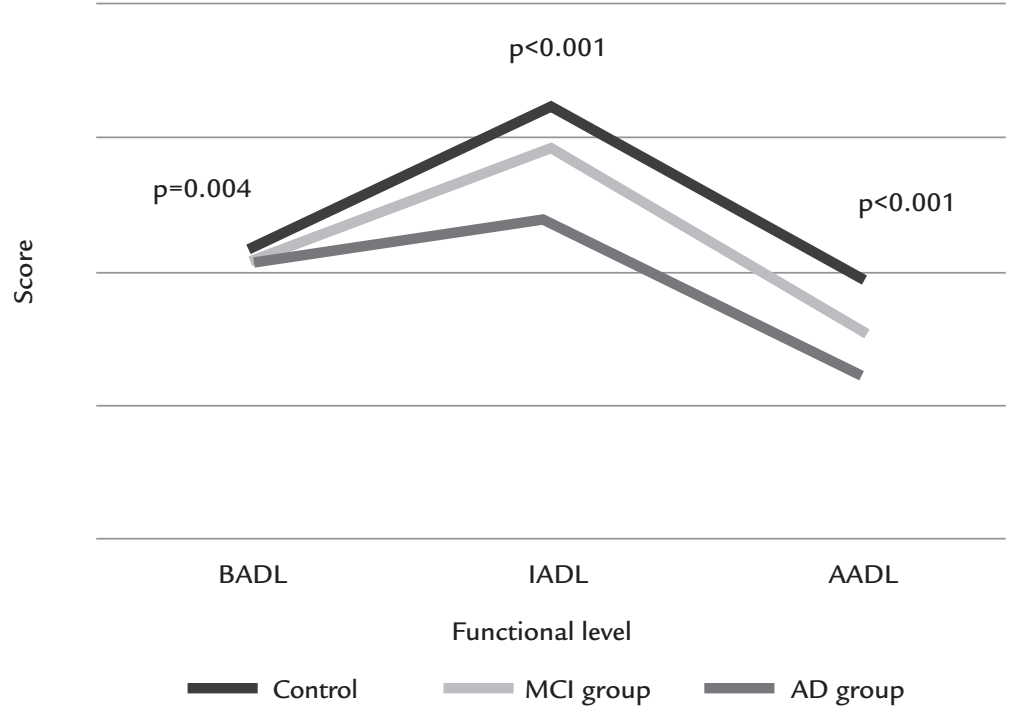

FIGURE 1 Characterization of the functional profile of the groups based on the mean points obtained by subdomain of the ADCS-ADL scale. MCI: mild cognitive impairment; AD: Alzheimer's disease; BADL: basic activities of daily living; IADL: instrumental activities of daily living; AADL: advanced activities of daily living.

BADL (6 questions), IADL (10 questions) and AADL (7 questions). This analysis was verified by Cronbach's alpha coefficient, yielding 0.89 . This value suggests a good correlation among domains. The Cronbach's coefficient was applied question to question rather than by domains (AADL, IADL and BADL), and in all cases the values found were higher than 0.80 .

\section{Criterion validity}

Our study's hypothesis that the constructs measured by the ADCS-ADL scale and the clinical and neuropsychological diagnoses would be associated and that this could be used as a diagnostic tool for MCI and AD was established and tested.

The results showed a significant association between the total ADCS-ADL scale and the clinical and neuropsychological diagnosis $(\mathrm{p}<0.001)$ with $\mathrm{ROC}_{\mathrm{c}}=0.89$. The AADL subdomain of the total ADCS-ADL scale presented a greater area under the curve $\left(\mathrm{ROC}_{\mathrm{c}}=0.92\right)$ in relation to the reference line (clinical and neuropsychological diagnosis). The results of these variables are close to those in the curve delimited by the Mattis scale $\left(\mathrm{ROC}_{\mathrm{c}}=0.918\right)$, whose study demonstrated greater diagnostic accuracy among study subjects, namely the control, MCI and AD. ${ }^{44}$ On the other hand, the Pfeffer IADL scale showed an area under the curve of 0.89 .

We established the cut-off point as 71 for the ADCS-ADL scale, to distinguish MCI and AD patients from controls, based on the sensitivity (Se) of $86.2 \%$, specificity (Sp) of $70.0 \%$, PPV of $86.2 \%$, NPV of $70.0 \%$ and accuracy of $81.1 \%$. The PLR was 2.9 and the NLR was 0.2 .

In order to differentiate the MCI subjects from the controls, the ADCS-ADL scale with a cut-off value of 71 points presents sensitivity of $75 \%$ and specificity of $70 \%$. To distinguish individuals with AD from the controls, we observed a sensitivity of $97.0 \%$ and specificity of $70 \%$. Finally, to discriminate between AD and MCI, we found a sensitivity of $97.0 \%$ and specificity of $25 \%$. The other quality tests of the scale carried out with the subitems IADL and BADL are described in Table 2 .

We demonstrated that the AADL subitem of the ADCS-ADL scale shows good accuracy to discriminate subjects from the control, MDI and AD groups, and is superior even to the full results of the scale. We established a cut-off of 18 points, and found the following results: Se: 90.8\%; Sp: 73.3\%; PPV: 88.1\%; NPV: 78.6\%; accuracy: $85.3 \%$. PLR was 3.4 and NLR was 0.1 .

The subitem AADL with a cut-off point of 18 points presents $84.4 \%$ sensitivity and $73.3 \%$ specificity to differentiate MCI subjects from controls. To distinguish individuals with AD from the controls, we detected a sensitivity of $97.0 \%$ and specificity of $73.3 \%$. To discriminate between $\mathrm{AD}$ and MCI, we obtained a sensitivity of $97.0 \%$ and specificity of $15.6 \%$. The data relating to IADL and BADL are described in Table 2. 
TABLE 2 Analysis of the quality measure of the ADCS-ADL scale.

Analysis of the total ADCS-ADL scale with cut-off value set at 71 points

\begin{tabular}{llllllll}
\hline & Se & Sp & PPV & NPV & Accuracy & PLR & NLR \\
\hline Cognitive decline (MCl and AD) versus controls & $86.2 \%$ & $70 \%$ & $86.2 \%$ & $70 \%$ & $81.1 \%$ & 2.9 & 0.2 \\
\hline $\mathrm{MCl}$ versus control & $75 \%$ & $70 \%$ & $72.7 \%$ & $72.4 \%$ & $72.6 \%$ & 2.5 & 0.4 \\
\hline AD versus control & $97 \%$ & $70 \%$ & $78 \%$ & $95.4 \%$ & $84.1 \%$ & 3.2 & 0.04 \\
\hline AD versus $\mathrm{MCl}$ & $97 \%$ & $25 \%$ & $42.9 \%$ & $88.9 \%$ & $61.5 \%$ & 1.3 & 0.1
\end{tabular}

Analysis of the AADL subitem of the ADCS scale with cut-off value set at 18 points

\begin{tabular}{|c|c|c|c|c|c|c|c|}
\hline & Se & Sp & PPV & NPV & Accuracy & PLR & NLR \\
\hline Cognitive decline ( $\mathrm{MCl}$ and $\mathrm{AD})$ versus controls & $90.8 \%$ & $73.3 \%$ & $88.1 \%$ & $78.6 \%$ & $85.3 \%$ & 3.4 & 0.1 \\
\hline $\mathrm{MCl}$ versus control & $84.4 \%$ & $73.3 \%$ & $77.1 \%$ & $81.5 \%$ & $79 \%$ & 3.2 & 0.2 \\
\hline$A D$ versus control & $97 \%$ & $73.3 \%$ & $80 \%$ & $95.7 \%$ & $85.7 \%$ & 3.6 & 0.04 \\
\hline$A D$ versus $M C l$ & $97 \%$ & $15.6 \%$ & $54.2 \%$ & $83.3 \%$ & $56.9 \%$ & 1.1 & 0.2 \\
\hline
\end{tabular}

Analysis of the IADL subitem of the ADCS-ADL scale with cut-off value set at 32 points

\begin{tabular}{|c|c|c|c|c|c|c|c|}
\hline & $\mathrm{Se}$ & Sp & PPV & NPV & Accuracy & PLR & NLR \\
\hline Cognitive decline ( $\mathrm{MCl}$ and $\mathrm{AD}$ ) versus controls & $81.5 \%$ & $76.7 \%$ & $88.3 \%$ & $65.7 \%$ & $80 \%$ & 3.5 & 0.2 \\
\hline $\mathrm{MCl}$ versus control & $68.8 \%$ & $76.7 \%$ & $75.9 \%$ & $69.7 \%$ & $72.6 \%$ & 3.0 & 0.4 \\
\hline$A D$ versus control & $93.9 \%$ & $76.7 \%$ & $81.6 \%$ & $92 \%$ & $85.7 \%$ & 4.0 & 0.08 \\
\hline$A D$ versus $M C l$ & $93.9 \%$ & $31.3 \%$ & $41.5 \%$ & $83.3 \%$ & $63.1 \%$ & 1.4 & 0.2 \\
\hline
\end{tabular}

Analysis of the BADL subitem of the ADCS-ADL scale with cut-off value set at 21 points

\begin{tabular}{|c|c|c|c|c|c|c|c|}
\hline & Se & Sp & PPV & NPV & Accuracy & PLR & NLR \\
\hline Cognitive decline ( $\mathrm{MCl}$ and $\mathrm{AD}$ ) versus controls & $66.2 \%$ & $63.3 \%$ & $79.6 \%$ & $46.3 \%$ & $65.3 \%$ & 1.8 & 0.9 \\
\hline $\mathrm{MCl}$ versus control & $68.8 \%$ & $63.3 \%$ & $66.7 \%$ & $65.5 \%$ & $66.1 \%$ & 1.9 & 0.5 \\
\hline$A D$ versus control & $63.6 \%$ & $63.3 \%$ & $65.6 \%$ & $61.3 \%$ & $63.5 \%$ & 1.7 & 0.6 \\
\hline$A D$ versus $M C l$ & $63.6 \%$ & $31.3 \%$ & $48.8 \%$ & $45.5 \%$ & $47.7 \%$ & 0.9 & 1.2 \\
\hline
\end{tabular}

ADCS-ADL: Alzheimer's Disease Cooperative Study - Activities of Daily Living; MCl: mild cognitive impairment; AD: Alzheimer's disease; Se: sensibility; Sp: specificity; PPV: positive predictive value; NPV: negative predictive value; PLR: positive likelihood ratio; NLR: negative likelihood ratio; AADL: advanced activities of daily living; IADL: instrumental activities of daily living; BADL: basic activities of daily living.

\section{Discussion}

Despite the great amount of knowledge regarding the description and monitoring of functional decline in the population with dementia, there is a gap in the literature with regard to the analysis of impairment of ADL in elderly people with $\mathrm{MCI}$, characterized as a pre-dementia symptomatic stage of AD. ${ }^{45}$

Several studies have aimed to characterize the nature of functional decline in this heterogeneous population, since the inclusion of the criterion "preservation of daily activities with slight impairment in complex activities" as a diagnostic for MCI in 2004. However, the unsystematic use and variability of the functional assessments employed have impaired more accurate results. ${ }^{46-49}$

We know that there are many scales for the assessment of ADL in the elderly. However, they were created with the objective of assessing the functional decline in elderly people with dementia, whose deficit proves to be more significant when compared to elderly people with MCI. ${ }^{48}$ This may create a "ceiling effect" in the instru- ment, masking the functional decline presented by individuals with MCI. ${ }^{50}$

In this context, the concern for early diagnosis is added to the need for instruments adapted and validated for the Brazilian population that assess the risk of dementia and MCI quickly, accurately and at a low cost. Our study aimed to perform a cultural adaptation, initial validation and analysis of the psychometric properties of the ADCS-ADL in view of its applicability and the satisfactory results observed in other studies. ${ }^{15,16,46,51}$ To our knowledge, this is one of the few Brazilian studies that describe the functional profile of elderly people with MCI, compared to that of elderly people with normal cognition and initial AD. ${ }^{16,46,52}$

The use of a scale based on information from third parties (caregivers or informants) seems to be the most suitable for assessing the functionality of elderly people with MCI, given that these elderly people often present anosognosia and do not recognize the extent of their difficulties. ${ }^{53-55}$ 
In our study, we were able to verify that there are different functional profiles among subjects with $\mathrm{MCI}, \mathrm{AD}$ and controls, with MCI assuming an intermediate pattern between the control group and the elderly with $\mathrm{AD}$. We also noted that elderly people with MCI presented deficits in AADL and IADL when compared to controls with normal cognition for age and educational level. Elderly people with $\mathrm{AD}$ also present deficits in these specific areas but functional decline is greater.

Our results resemble those of Perneczky et al. and Pereira et al. ${ }^{46,56}$ They found that elderly individuals with MCI presented a functional decline in complex ADL compared to control subjects. The literature on the subject reveals that despite variability in the use of ADL assessment scales, several studies have identified a decline in AADL (exercise of roles and social activities typical of adult life) and IADL (management of domestic and community practical life) in elderly people with MCI. ${ }^{47-49,57}$

It is important to emphasize that this type of instrument can be influenced by factors such as the level of caregiver overload, degree of proximity and the emotional state of the informant..$^{58}$ To reduce the chance of error, the ADCS-ADL scale also has a manual with clear and objective explanations for all items. Another positive point is that it assesses the individual's actual performance in a month, and therefore excludes the caregiver's opinion about what the individual could do if they presented conditions to do so, as well as what the caregiver subjectively thinks with respect to the subject assessed.

It was verified that few items were left unanswered (8.7\%), which contributes to the high internal validity of the test. Most caregivers were close relatives. However, a small percentage (17.4\%) were comprised of other relatives, which may have contributed to the unanswered items.

It is important to emphasize that some items in the IADL and BADL subdomains of the ADCS-ADL scale may be influenced by the gender variable, such as cooking, using cutlery and washing and ironing. Culturally, these activities are carried out by Brazilian women. ${ }^{59}$ As previously described, the necessary adaptations were performed after pre-testing applications, adjusting the test to the cultural demands by gender.

Regarding the analysis of the psychometric properties, the ADCS-ADL scale provided good reliability, also verified in the study by Pedrosa et al. ${ }^{16}$ In addition, the study presented a moderate Se value in the control-MCI differentiation (75\%) and high Se value to differentiate AD-control (97\%). However, there were moderate $\mathrm{Sp}$ values in both cases $(70 \%)$.

According to the analyses regarding the differentiation of the MCI-AD group, the scale showed a high Se value $(97 \%)$ and low Sp value (25\%), which indicates that it is effective in the discrimination of this group. It should be noted that our specificity values are lower than those presented in the study by Pedrosa et al. ${ }^{16}$

We can infer from these results that the ADCS-ADL scale constitutes a test with high Se and moderate Sp, presenting greater power to detect people with cognitive impairment, although susceptible to false positives, especially in the differentiation between AD-control and $\mathrm{MCI}-\mathrm{AD}$. The scale was reasonable in the distinction between control-MCI. It can be used as a screening instrument for identifying individuals at risk of $\mathrm{MCI}$ or $\mathrm{AD}$, requiring further evaluation in order to define the diagnosis. ${ }^{60}$

We believe the ADCS-ADL scale to be a viable instrument as it is easy to apply, and external materials or resources are not required for its completion. Furthermore, it is quick to apply, especially compared to other diagnostic assessment instruments.

When analyzing the psychometric properties of the subitems in the ADCS-ADL scale, we are faced with the fact that AADL, composed of seven questions, presents results superior to the full scale in discriminating between control, $\mathrm{MCI}$ and $\mathrm{AD}$ patients, especially for differentiating the subjects with MCI from the controls more effectively than the full version of the ADCS-ADL scale. In addition, this subitem presents results only slightly below those obtained using the Mattis scale and above those in the Pfeffer ADL scale, when evaluated using the ROC curve. However, this subitem needs to be evaluated in the future as a reduced version of the ADCS-ADL scale with the same psychometric properties as the full scale.

It should be noted that the AADL subitem presents high sensitivity and a PLR value close to 0.1 . These properties point to the potential of using the questionnaire as a screening tool, which reinforces the possibility of it being applied in primary care. This fact is of extreme importance in view of the difficulty in identifying these patients in primary health care, which has an impact on the diagnosis and management of cognitive and functional disorders, especially when considering early diagnosis. It should be noted that the data relating to the AADL subdomain are not comparable, given that no other study with the full scale has adopted this division.

In primary care, initial $\mathrm{AD}$ and $\mathrm{MCI}$ are often not diagnosed. Data from the literature show that in developed countries only 20 to $50 \%$ of patients with dementia are diagnosed, whereas in some underdeveloped countries the rate is less than $10 \% .{ }^{4}$ These data reinforce the importance of the results found in the AADL subitem. Given the above, we suggest validation studies in primary care, especially 
those involving community health agents or nurses at health centers.

The Pfeffer Instrumental Activities Questionnaire presented $\mathrm{ROC}=0.89$, close to the values shown by the ADCS-ADL scale. It is worth noting that the scale was originally described for functional assessment, and was mainly used to evaluate initial AD with Se: $85 \%$ and Sp: $81 \%{ }^{27}$ There is no cut-off point defined for $\mathrm{MCI}$ in the analysis of all the existing versions of the test in Brazil, with a cut-off point of 3 and 5 points described for functional impairment and functional incapacity, respectively. ${ }^{61}$ Studies for screening cognitive impairment in elderly populations with low levels of education, such as in Brazil, indicate that the use of Pfeffer's instrumental activities questionnaire is not sufficient for adequate screening of cognitive decline, and other cognitive tests must be combined to obtain suitable sensitivity and specificity values. ${ }^{62}$

Our study has limitations given that the scale is not yet validated due to the absence of the peer evaluation phase. The validation process for the Brazilian Portuguese version must be completed, despite the existence of a validated version in Portuguese from Portugal. ${ }^{63}$ Brazil and Portugal, although adopting the same official language, hold profound cultural and linguistic differences, which justify the need for a separate validation for each country ${ }^{64}$ Furthermore, it is important to highlight the differences resulting from the influence of different levels of education among the elderly population of the two countries. ${ }^{65}$ The authors of the original scale have given their authorization for cross-cultural adaptation in Brazil, which did not extend to disclosure in the original format and in the adapted version, therefore the ADCS-ADL scale is not attached to this article.

We conclude that the translated version of the ADCS-ADL adapted to Brazilian Portuguese has satisfactory psychometric properties to differentiate patients with cognitive incapacity from those with MCI. In view of the psychometric properties described for the AADL subitem of the ADCS-ADL scale, we suggest validation of this reduced version as a possible functional screening tool in primary care.

\section{Conflict of Interest}

The authors declare no conflict of interest.

\section{Resumo}

Declínio funcional em idosos com comprometimento cognitivo leve: adaptação cultural da escala ADCS-ADL.
Objetivo: Tradução, adaptação transcultural para o português brasileiro e aplicação da escala Alzheimer's Disease Cooperative Study - Activities of Daily Living (ADCS-ADL) como instrumento de triagem cognitiva.

Método: Retrotradução associada ao método bilíngue e de pré-teste. A amostra foi constituída por 95 idosos e seus respectivos acompanhantes, sendo 30 controles, 32 portadores de comprometimento cognitivo leve (CCL) e 33 portadores de demência de Alzheimer (DA) em fase inicial.

Resultados: Um pequeno número de modificações ocorreu na escala. O coeficiente alpha de Cronbach foi 0,89 . O grupo controle pontuou 72,9 , seguido pelo CCL $(65,1)$ e pelo DA $(55,9)$, valor $\mathrm{p}<0,001$. A curva ROC demonstrou valor de 0,89 . Com o ponto de corte de 72 , observamos sensibilidade de $86,2 \%$, especificidade de $70 \%$, valor preditivo positivo de $86,2 \%$, valor preditivo negativo de $70 \%$, razão de verossimilhança positiva de 2,9 e razão de verossimilhança negativa de 0,2 .

Conclusão: A escala ADCS-ADL apresenta propriedades psicométricas satisfatórias para discriminar entre DA, CCL e cognição normal.

Palavras-chave: comprometimento cognitivo leve, demência de Alzheimer, atividades cotidianas.

\section{References}

1. Miranda GMD, Mendes ACG, Silva ALA. O envelhecimento populacional brasileiro: desafios e consequências. Rev Bras Geriatria Gerontol. 2016; 19(3):507-19.

2. Ramos-Cerqueira AT, Torres AR, Crepaldi AL, Oliveira NI, Scazufca M, Menezes PR, et al. Identification of dementia in the community: a Brazilian experience. J Am Geriatr Soc. 2005; 53(10):1738-42.

3. Chaimowicz F. A saúde dos idosos brasileiros às vésperas do século XXI: problemas, projeções e alternativas. Rev Saúde Pública. 1997; 31(2):184-200.

4. Prince M, Bryce R, Ferri C. Alzheimer's Disease International World Alzheimer Report 2011 - The benefits of early diagnosis and intervention. Institute of Psychiatry, King's College London, UK. Published by Alzheimer's Disease International (ADI); 2011 [cited 2015 Sep 15]. Available from: https://www. alz.co.uk/research/WorldAlzheimerReport2011.pdf.

5. Albert MS, DeKosky ST, Dickson D, Dubois B, Feldman HH, Fox NC, et al. The diagnosis of mild cognitive impairment due to Alzheimer's disease: recommendations from the National Institute on Aging-Alzheimer's Association workgroups on diagnostic guidelines for Alzheimer's disease. Alzheimers Dement. 2011; 7(3):270-9.

6. Kelley BJ, Petersen RC. Alzheimer's disease and mild cognitive impairment, Neurol Clin. 2007; 25(3):577-609.

7. Petersen RC, Negash S. Mild cognitive impairment: an overview. CNS Spectr. 2008; 13(1):45-53.

8. Petersen RC. Mild cognitive impairment as a diagnostic entity. J Intern Med. 2004; 256(3):183-94.

9. Bangen KJ, Jak AJ, Schiehser DM, Delano-Wood L, Tuminello E, Han SD, et al. Complex activities of daily living vary by mild cognitive impairment subtype. J Int Neuropsychol Soc. 2010; 16(4):630-9.

10. Pereira FS, Yassuda MS, Oliveira AM, Diniz BS, Radanovic M, Talib LL, et al. Profiles of functional deficits in mild cognitive impairment and dementia: benefits from objective measurement. J Int Neuropsychol Soc. 2010; 16(2):297-305.

11. Marshall GA, Olson LE, Frey MT, Maye J, Becker JA, Rentz DM, et al. Instrumental activities of daily living impairment is associated with increase amyloid burden. Dement Geriatr Cogn Disord. 2011; 31(6):443-50. 
12. Farias ST, Mungas D, Reed BR, Harvey D, Cahn-Weiner D, Decarli C. MCI is associated with deficits in everyday functioning. Alzheimer Dis Assoc Disord. 2006; 20(4):217-23.

13. Nitrini R, Caramelli P, Bottino CMC, Damasceno BP, Brucki SMD, Anghinah R. Diagnóstico de doença de Alzheimer no Brasil: avaliação cognitiva e funcional. Recomendações do Departamento Científico de Neurologia Cognitiva e do Envelhecimento da Academia Brasileira de Neurologia. Arq Neuropsiquiatr. 2005; 63(3A):720-7.

14. Galasko D, Bennett D, Sano M, Ernesto C, Thomas R, Grundman M, et al. An inventory to assess activities of daily living for clinical trials in Alzheimer's disease. The Alzheimer's Disease Cooperative Study. Alzheimer Dis Assoc Disord. 1997; 11 (Suppl 2):S33-9.

15. Grundman M, Petersen RC, Ferris SH, Thomas RG, Aisen PS, Bennett DA et al.; Alzheimer's Disease Cooperative Study. Mild cognitive impairment can be distinguished from Alzheimer disease and normal aging for clinical trials. Arch Neurol. 2004; 61(1):59-66.

16. Pedrosa H, De Sa A, Guerreiro M, Maroco J, Simoes MR, Galasko D, et al. Functional evaluation distinguishes MCI patients from healthy elderly peoplethe ADCS/MCI/ADL scale. J Nutr Health Aging. 2010; 14(8):703-9.

17. Beaton DE, Bombardier C, Guillemin F, Ferraz MB. Guidelines for the process of cross-cultural adaptation of self-report measures. Spine. 2000; 25(24):3186-91

18. McKhann GM, Knopman DS, Chertkow H, Hyman BT, Jack CR Jr, Kawas $\mathrm{CH}$, et al. The diagnosis of dementia due to Alzheimer's disease: recommendations from the National Institute on Aging-Alzheimer's Association workgroups on diagnostic guidelines for Alzheimer's disease. Alzheimers Dement. 2011; 7(3):263-9.

19. Morris JC. The Clinical Dementia Rating (CDR): current version and scoring rules. Neurology. 1993; 43(11):2412-4

20. Petersen RC, Stevens JC, Ganguli M, Tangalos EG, Cummings JL, DeKosky ST. Practice parameter: early detection of dementia: mild cognitive impairment (an evidence-based review). Report of the Quality Standards Subcommittee of the American Academy of Neurology. Neurology. 2001; 56(9):1133-42.

21. Folstein MF, Folstein SE, McHugh PR. "Mini-mental state". A practical method for grading the cognitive state of patients for the clinician. J Psychiatr Res. 1975; 12(3):189-98.

22. Henry JD, Crawford JR, Phillips LH. Verbal fluency performance in dementia of the Alzheimer's type: a meta-analysis. Neuropsychologia. 2004; 42(9):1212-22.

23. Almeida OP, Almeida SA. Confiabilidade da versão brasileira da escala de depressão em geriatria (GDS) versão reduzida. Arq Neuropsiquiatr. 1999; 57(2B):421-6.

24. Shulman KI. Clock-drawing: is it the ideal cognitive screening test? Int J Geriatr Psychiatry. 2000; 15(6):548-61.

25. Morris JC, Heyman A, Mohs RC, Hughes JP, van Belle G, Fillenbaum G, et al. The Consortium to Establish a Registry for Alzheimer's Disease (CERAD): Part I. Clinical and neuropsychological assessment of Alzheirmer's disease. Neurology. 1989; 39(9):1159-65.

26. Reisberg B, Borenstein J, Salob SP, Ferris SH, Franssen E, Georgotas A. Behavioral symptoms in Alzheimer's disease: phenomenology and treatment. J Clin Psychiatry. 1987; 48 (Suppl):9-15.

27. Pfeffer RI, Kurosaki TT, Harrah CH Jr, Chance JM, Filos S. Measurement of functional activities in older adults in the community. J Gerontol. 1982; 37(3):323-9.

28. Nitrini R, Lefevre BH, Mathias SC, Caramelli P, Carrilho PEM, Sauaia N, et al. Testes neuropsicológicos de aplicação simples para o diagnóstico de demência. Arq Neuropsiquiatr. 1994; 52(4):457-65.

29. Marin RS, Biedrzycki RC, Firinciogullari S. Reliability and validity of the Apathy Evaluation Scale. Psychiatry Res. 1991; 38(2):143-62 .

30. Guimarães HC, Fialho PPA, Carvalho VA, Santos EL, Caramelli P. Brazilian caregiver version of the Apathy Scale. Dement Neuropsychol. 2009; 3(4):321-6.

31. Reisberg B. Functional assessment staging (FAST). Psychopharmacol Bull. 1988; 24(4):653-9.

32. Cummings JL, Mega M, Gray K, Rosenberg-Thompson S, Carusi DA, Gornbein J. The Neuropsychiatric Inventory: comprehensive assessment of psychopathology in dementia. Neurology. 1994; 44(12): 2308-14

33. American Psychiatric Association, APA. Manual Diagnóstico e Estatístico de Transtornos Mentais. DSM-IV-TR. 4. ed. Porto Alegre: Artmed; 2002.

34. Mattis S. Dementia Rating Scale. Professional Manual. Florida: Psychological Assessment Resources; 1988.
35. Porto CS, Fichman HC, Caramelli P, Bahia VS, Nitrini R. Brazilian version of the Mattis dementia rating scale diagnosis of mild dementia in Alzheimer's disease. Arq Neuropsiquiatr. 2003; 61(2B):339-45.

36. Nascimento E. WAIS-III: manual para administração e avaliação. São Paulo: Casa do Psicólogo; 2004.

37. Corsi, PM. Human memory and the medial temporal region of the brain [thesis]. Montreal: McGill University; 1972.

38. Paula JJ, Schlottfeldt CG, Moreira L, Cotta M, Bicalho MA, Romano-Silva MA, et al. Propriedades psicométricas de um protocolo neuropsicológico breve para uso em populações geriátricas. Rev Psiquiatra Clín. 2010; 37(6):246-50.

39. De Renzi E, Faglioni P. Normative data and screening power of a shortened version of the Token Test. Cortex. 1978; 14(1):41-9.

40. Radanovic M, Mansur LL, Azambuja MJ, Porto CS, Scaff M. Contribution to the evaluation of language disturbances in subcortical lesions: a piloty study. Arq Neuropsiquiatr. 2004; 62(1):51-7.

41. Rey A. L'examen clinique en psychologie: 2. et. Le psychologue, 1. Paris: Presses Universitaires de France; 1998

42. Malloy-Diniz LF, Lasmar VA, Gazinelli Lde S, Fuentes D, Salgado JV. The Rey Auditory-Verbal Learning Test: applicability for the Brazilian elderly population. Rev Bras Psiquiatr. 2007; 29(4):324-9.

43. Paula JJ, Malloy-Diniz LF. Executive functions as predictors of functional performance in mild Alzheimer's dementia and mild cognitive impairment elderly. Estud Psicol (Natal). 2013; 18(1):117-24.

44. de Paula JJ, Bertola L, Ávila RT, Moreira L, Coutinho G, de Moraes EN, et al. Clinical applicability and cutoff values for an unstructured neuropsychological assessment protocol for older adults with low formal education. PLoS ONE. 2013; 8(9):e73167.

45. Belchior P, Korner-Bitensky N, Holmes M, Robert A. Identification and assessment of functional performance in mild cognitive impairment: a survey of occupational therapy practices. Aust Occup Ther J. 2015; 62(3):187-96.

46. Perneczky R, Pohl C, Sorg C, Hartmann J, Tosic N, Grimmer T, et al. Impairment of activities of daily living requiring memory or complex reasoning as part of the MCI syndrome. Int J Geriatr Psychiatry. 2006; 21(2):158-62.

47. Brown PJ, Devanand DP, Liu X, Caccappolo E; Alzheimer's Disease Neuroimaging Initiative. Functional impairment in elderly patients with mild cognitive impairment and mild Alzheimer disease. Arch Gen Psychiatry. 2011; 68(6):617-26

48. Marshall GA, Amariglio RE, Sperling RA, Rentz DM. Activities of daily living: where do they fit in the diagnosis of Alzheimer's disease? Neurodegener Dis Manag. 2012; 2(5):483-91.

49. Yeh YC, Lin KN, Chen WT, Lin CY, Chen TB, Wang PN. Functional disability profiles in amnestic mild cognitive impairment. Dement Geriatr Cogn Disord. 2011; 31(3):225-32.

50. Maher CG, Latimer J, Costa LOP. A importância da adaptação transcultural e clinimétrica para instrumentos de fisioterapia. Rev Bras Fisioter. 2007; 11(4):245-52

51. Li M, Ng TP, Kua EH, Ko SM. Brief informant screening test for mild cognitive impairment and early Alzheimer's disease. Dement Geriatr Cogn Disord. 2006; 21(5-6):392-402.

52. Galasko D, Bennett DA, Sano M, Marson D, Kaye J, Edland SD; Alzheimer's Disease Cooperative Study. ADCS Prevention Instrument Project: assessment of instrumental activities of daily living for community-dwelling elderly individuals in dementia prevention clinical trials. Alzheimer Dis Assoc Disord. 2006; 20(4 Suppl 3):S152-69.

53. Almeida OP, Crocco EI. Percepção dos déficits cognitivos e alterações do comportamento em pacientes com doença de Alzheimer. Arq Neuropsiquiatr. 2000; 58(2A):292-9

54. Carr DB, Gray S, Baty J, Morris JC. The value of informant versus individual's complaints of memory impairment in early dementia. Neurology. 2000; 55(11):1724-6

55. Spalletta G, Girardi P, Caltagirone C, Orfei MD. Anosognosia and neuropsychiatric symptoms and disorders in mild Alzheimer disease and mild cognitive impairment. J Alzheimers Dis. 2012; 29(4):761-72.

56. Pereira FS, Yassuda MS, Oliveira AM, Forlenza OV. Executive dysfunction correlates with impaired functional status in older adults with varying degrees of cognitive impairment. Int Psychogeriatr. 2008; 20(6):1104-15.

57. De Vriendt P, Gorus E, Cornelis E, Velghe A, Petrovic M, Mets T. The process of decline in advanced activities of daily living: a qualitative explorative study in mild cognitive impairment. Int Psychogeriatr. 2012; 24(6):974-86.

58. Paixão CM Jr, Reichenheim ME. [A review of functional status evaluation instruments in the elderly]. Cad Saúde Pública. 2005; 21(1):7-19. 
59. Duarte YA, Lebrão ML, Lima FD. Contribuição dos arranjos domiciliares para o suprimento de demandas assistenciais dos idosos com comprometimento funcional em São Paulo, Brasil. Rev Panam Salud Publica. 2005; 17(5-6):370-8.

60. Pagano M, Gauvreau K. Princípios de Bioestatística. São Paulo: Cengage Learning; 2010

61. Assis LO, Assis MG, de Paula JJ, Malloy-Diniz LF. O questionário de atividades funcionais de Pfeffer: revisão integrativa da literatura brasileira. Estud Interdiscipl Envelhec. 2015; 20(1):297-324.

62. Jacinto AF, Brucki SM, Porto CS, Martins MA, Citero VA, Nitrini R. Suggested instruments for General Practitioners in countries with low schooling to screen for cognitive impairment in the elderly. Int Psychogeriatr. 2014; 26(7):1121-5

63. Pedrosa HMD. Avaliação Funcional em doentes com Defeito Cognitivo Ligeiro: a escala ADCS MCI ADL [dissertation]. Lisboa: Faculdade de Medicina de Lisboa, Universidade de Lisboa; 2007.

64. Reichenheim ME, Moraes CL. Operacionalização de adaptação transcultural de instrumentos de aferição usados em epidemiologia. Rev Saúde Pública. 2007; 41(4):665-73

65. Dias EG, Andrade FB, Duarte YA, Santos JL, Lebrão ML. [Advanced activities of daily living and incidence of cognitive decline in the elderly: the SABE Study]. Cad Saúde Pública. 2015; 31(8):1623-35. 